\title{
Establishing an approach to mechanical ventilation
}

\author{
THOMAS E STEWART MD FRCPC \\ Division of Respirology, Ewart Angus ICU, The Wellesley Hospital, University of Toronto, \\ Toronto, Ontario
}

TE STEWART. Establishing an approach to mechanical ventilation. Can Respir J 1996;3(6):403-408.

Technology in the intensive care environment has progressed at an exponential rate. This progression has particularly been noticeable in relation to mechanical ventilation where advancements have arguably surpassed improvements in patient morbidity and mortality. Ventilator-induced lung injury (VILI), which occurs secondary to lung overdistension and underinflation, may largely be responsible for this discrepancy. No matter which of the vast number of modes of mechanical ventilation are employed, simple principles can be followed that will prevent the development of VILI. A lung protective ventilatory approach incorporates the prevention of oxygen toxicity and the avoidance of lung over- and underinflation, while frequently using permissive hypercapnia. By establishing a lung protective approach early in the management of ventilated patients, the morbidity and mortality associated with respiratory failure may finally be reduced.

Key Words: Ventilator-induced lung injury

\section{Définir une approche pour la ventilation mécanique}

RÉSUMÉ : La technologie dans le domaine des soins intensifs a crû de manière exponentielle, en particulier celle en matière de ventilation mécanique où l'on peut dire que les progrès dépassent ceux obtenus en terme de mortalité et de morbidité des patients. Les traumatismes pulmonaires induits par le ventilateur, souvent secondaires à une surdistension ou à une inflation insuffisante, pourraient en grande partie expliquer cette discordance. Quel que soit le mode de ventilation mécanique utilisé, on peut appliquer des règles simples pour prévenir les traumatismes pulmonaires induits par le ventilateur. Une approche de la ventilation qui privilégie la protection du poumon exige de prévenir la toxicité de l'oxygène et d'éviter une surdistension ou une inflation insuffisante des poumons, tout en faisant fréquemment usage de l'hypercapnie contrôlée. En définissant une approche de protection du poumon dès le début de la prise en charge des patients ventilés mécaniquement, la morbidité et la mortalité associées à l'insuffisance respiratoire pourraient enfin régresser.
$\mathrm{T}$ he majority of patients requiring mechanical ventilation do so for very brief periods of time such as during the operative and perioperative period. For the most part these patients have good lung function and generally tolerate mechanical ventilation with conventional tidal volumes (VT) of 10 to $15 \mathrm{~mL} / \mathrm{kg}$ without developing any adverse effects. On the other hand, patients in the intensive care environment frequently have or are at high risk for lung inflammation and injury, and may be prone to ventilator-induced lung injury
(VILI). VILI encompasses the spectrum of lung injury caused by mechanical ventilation. Classically, VILI was most commonly recognized clinically as pneumomediastinum, pneumoperitoneum, subcutaneous emphysema, pulmonary interstitial emphysema, systemic gas embolism and pneumothorax. These forms of VILI, which result from rupture of alveoli and subsequent tracking of air along the perivascular sheaths, are generally not thought to occur until airway pressures exceed $50 \mathrm{~cm} \mathrm{H}_{2} \mathrm{O}(1,2)$. More recently it has been

Correspondence and reprints: Dr Thomas E Stewart, Room 245, Jones Building, The Wellesley Hospital, 160 Wellesley Street East, Toronto, Ontario M4Y 1J3. Telephone 416-926-7962, fax 416-926-5140, e-mail tom.stewart@utoronto.ca 


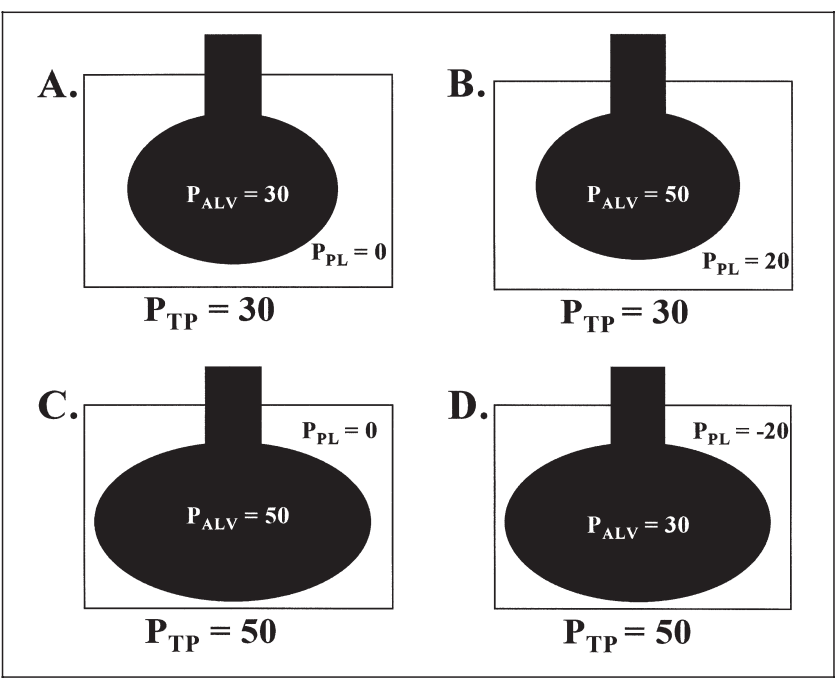

Figure 1) Four diagrammatic representations of an alveolus (black solid object) inside a chest wall (box) separated by the pleural space. Transpulmonary pressure $\left(P_{T P}\right)$ is the alveolar pressure $\left(P_{A L V}\right)$ minus the pleural pressure $\left(P_{P L}\right)$. A The recorded alveolar pressure is 30 while the pleural pressure is 0 ; thus, the transpulmonary pressure is 30 and the alveolus is maximally distended. B Although the alveolar pressure is very high (50), overdistension is avoided by an increase in pleural pressure, and thus the transpulmonary pressure remains 30. Example of this clinical situation are pleural effusions, abdominal distention and chest wall bandages. C The alveolar pressure is high and it is not opposed by high pleural pressures; thus, the alveolus becomes overdistended and exposed to ventilator-induced lung injury. D Although alveolar pressure remains relatively low, the alveolus is overdistended $\left(P_{T P}=50\right)$ due to a very negative pleural pressure; a clinical scenario that this might be associated with is large patient effort or negative pressure ventilation

recognized (primarily from animal work) that VILI not only encompasses these air leaks but also may be manifested as high permeability pulmonary edema, hyaline membrane formation, decreased lung compliance, atelectasis, hypoxemia, etc, all of which are difficult to separate from the clinical and pathological features of acute respiratory distress syndrome (ARDS). This type of injury appears to occur at relatively low airway pressures and volumes that are commonly used clinically today. The implication (which is supported by the literature) is that traditional forms of ventilation may be imposing further damage on some patients, and that if clinicians employ ventilation strategies aimed at reducing VILI the morbidity and mortality of patients with lung injury may be reduced.

\section{VENTILATOR-INDUCED LUNG INJURY}

Role of pressure: One of the earlier studies addressing the role of pressure was by Webb and Tierney (3) in 1974. They demonstrated that when normal rats are ventilated with peak inspiratory pressures (PIPs) in excess of $30 \mathrm{~cm} \mathrm{H}_{2} \mathrm{O}$ (VT $29 \mathrm{~mL} / \mathrm{kg}$ ) for $1 \mathrm{~h}$, pulmonary edema develops. This edema was only perivascular at a $\mathrm{PIP}$ of $30 \mathrm{~cm} \mathrm{H}_{2} \mathrm{O}$, but became alveolar edema associated with increased hypoxemia and reduced lung compliance at $45 \mathrm{~cm} \mathrm{H}_{2} \mathrm{O}$ (VT $45 \mathrm{~mL} / \mathrm{kg}$ ). In a subsequent study, Dreyfuss et al (4) demonstrated that very brief exposure (as brief as 5 mins) of rats to high PIP (45 cm $\mathrm{H}_{2} \mathrm{O}$ ) resulted in endothelial disruption and an increase in microvascular permeability leading to peribronchovascular edema. These lesions were accompanied by high permeability alveolar edema, epithelial disruption and hyaline membranes when the exposure to the high pressure exceeded 20 mins. Similar findings have been confirmed in other animals such as sheep and dogs (5-7). The histological lesions of VILI progress in sequence from perivascular edema and endothelial injury to interstitial edema, on to epithelial injury and finally alveolar edema. Since high PIPs were commonly associated with these lesions, this form of VILI was originally referred to as barotrauma, although absolute pressure is not the only important factor.

Role of lung stretching: In the above studies the animals that developed VILI were exposed not only to high PIP but also to very high VT (20 to $70 \mathrm{~mL} / \mathrm{kg}$ ). Dreyfuss et al (8) attempted to determine which of these (PIP or VT) was the major cause of VILI. In their study, normal rats were randomly assigned to ventilation for $20 \mathrm{mins}$ in one of the following groups: (1) control: $\mathrm{PIP}=7 \mathrm{~cm} \mathrm{H}_{2} \mathrm{O}$, positive end-expiratory pressure (PEEP) $=0 \mathrm{~cm} \mathrm{H}_{2} \mathrm{O}, \mathrm{VT}=13 \mathrm{~mL} / \mathrm{kg}$; (2) high pressure high volume: $\mathrm{PIP}=45 \mathrm{~cm} \mathrm{H}_{2} \mathrm{O}, \mathrm{PEEP}=$ $0 \mathrm{~cm} \mathrm{H}{ }_{2} \mathrm{O}, \mathrm{VT}=40 \mathrm{~mL} / \mathrm{kg}$; (3) high pressure low volume (achieved by strapping the rat's chest wall with elastic

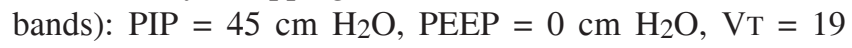
$\mathrm{mL} / \mathrm{kg}$; and (4) low pressure high volume (achieved using a negative pressure ventilator): $\mathrm{PIP}=$ negative, $\mathrm{PEEP}=0 \mathrm{~cm}$ $\mathrm{H}_{2} \mathrm{O}$, VT $=44 \mathrm{~mL} / \mathrm{kg}$. The end-points were macro- and microscopic changes, lung edema and protein leak. They found that more lung injury occurred in the two groups that were exposed to high volume (groups 2 and 4) than in those exposed to high pressure but low volume. They concluded that the key factor in the development of VILI is the total volume that the lung is exposed to and not the pressure per se. Thus VILI has been recognized as volutrauma rather than barotrauma because distending volume rather than pressure appeared to most important.

The key factor probably is the transpulmonary pressure (РTP) that the alveoli are exposed to. $\mathrm{P}_{\mathrm{TP}}$ is the difference in pressure between the alveolus ( $\left.\mathrm{P}_{\mathrm{ALV}}\right)$ and the pleural space (PPL):

$$
\mathrm{P}_{\mathrm{TP}}=\mathrm{P}_{\mathrm{ALV}}-\mathrm{P}_{\mathrm{PL}}
$$

Lung distention is directly related to PTP. Normal lung tissue reaches its maximum distention when $\mathrm{P}_{\mathrm{TP}}$ reaches 30 to 35 $\mathrm{cm} \mathrm{H}_{2} \mathrm{O}$ (9). In the study of Dreyfuss et al (8) the animals in the high pressure low volume group probably did not demonstrate as much VILI because their PTP was limited by chest wall strapping, which caused a rise in PPL. This would explain why the animals in the negative pressure ventilation arm developed VILI: their PPL would be very negative, resulting in high PTP despite a low PALV. The importance of PTP as the cause of VILI explains why, when extremely high airway pressures are generated that are offset by high PPL (such as during coughing, sneezing, weight lifting, straining, etc), VILI does not occur (Figure 1). The importance of lung 
overdistension (or $\mathrm{P}_{\mathrm{TP}}$ ) as opposed to the absolute airway pressure has been confirmed in other studies $(10,11)$.

Role of inadequate end-expiratory volumes: It is important to note that the lung injury caused by overdistension was reduced (particularly alveolar flooding) by the use of PEEP in two of the above studies $(3,8)$. This has led to debate over the role of maintaining some end-expiratory lung volume in order to prevent VILI. Sandhar et al (12), using a rabbit lung injury model, demonstrated that rabbits ventilated with PEEP above the inflection point $\left(\mathrm{P}_{\text {flex }}\right)$ on the pressure volume curve (the point at which the slope of the inflation limb turns most upright, see Figure 2) as opposed to PEEP well below Pflex (approximately $3 \mathrm{~cm} \mathrm{H} 2 \mathrm{O}$ ) developed less progressive lung injury. In a canine acid aspiration model, dogs ventilated for $5 \mathrm{~h}$ with VT $30 \mathrm{~mL} / \mathrm{kg}$ and PEEP $3 \mathrm{~cm} \mathrm{H} 2 \mathrm{O}$ developed more pulmonary edema, hypoxemia and venous admixture than a group ventilated with VT $15 \mathrm{~mL} / \mathrm{kg}$ and PEEP $12 \mathrm{~cm}$ $\mathrm{H}_{2} \mathrm{O}$, despite having the same peak airway pressures, peak inspiratory lung volumes and pulmonary capillary wedge pressures (13). Some have argued, however, that this apparent protective effect of PEEP may be due largely to its effect on lowering cardiac output and, thus, preventing lung edema. This was speculated after rats protected from VILI with PEEP had a resurgence of lung injury following the addition of dopamine to maintain cardiac output (11). In order to separate the direct effects from the hemodynamic consequences of PEEP, Muscedere et al (14) studied isolated lavaged rat lungs and demonstrated that PEEP below the $\mathrm{P}_{\text {flex }}$ exacerbated lung injury, independently of hemodynamic effects. They suggested that VILI occurs with inadequate PEEP when opposing surfaces are repeatedly allowed to close followed by reopening, in effect causing shear injury.

In summary, animal evidence has consistently demonstrated that VILI also incorporates a spectrum of injury that may be less commonly recognized clinically than the classical forms of barotrauma. The damage appears to be independently created by high $\mathrm{P}_{\mathrm{TP}}$ (greater than 30 to $35 \mathrm{~cm} \mathrm{H}_{2} \mathrm{O}$ ) and the inadequate use of PEEP (less than $\mathrm{P}_{\text {flex }}$ ). The injury, which incorporates high permeability interstitial and alveolar edema as well as endothelial disruption, epithelial disruption and hyaline membrane formation (lesions similar to those found in ARDS), can be induced after a short period of ventilation in healthy lungs and can exacerbate the damage in previously injured lungs.

\section{LUNG PROTECTIVE VENTILATION STRATEGIES}

Many now believe that animal findings are relevant to the care of mechanically ventilated humans. It is speculated that lung injury can be caused or exacerbated by conventional ventilatory techniques. If clinicians are attempting to limit the impact mechanical ventilation has on morbidity and mortality, current recommendations for a lung protective ventilation strategy (LPVS) suggest that, apart from limiting fraction of inspired oxygen $\left(\mathrm{FiO}_{2}\right)$ to prevent oxygen toxicity $\left(\mathrm{FiO}_{2}\right.$ less than 0.5 to 0.6 ), $\mathrm{P}_{\text {TP }}$ greater than 30 to $35 \mathrm{~cm} \mathrm{H}_{2} \mathrm{O}$ as well as PEEP less than $\mathrm{P}_{\text {flex }}$ should be avoided (15).

PEEP: Historically, PEEP has been used by clinicians in an

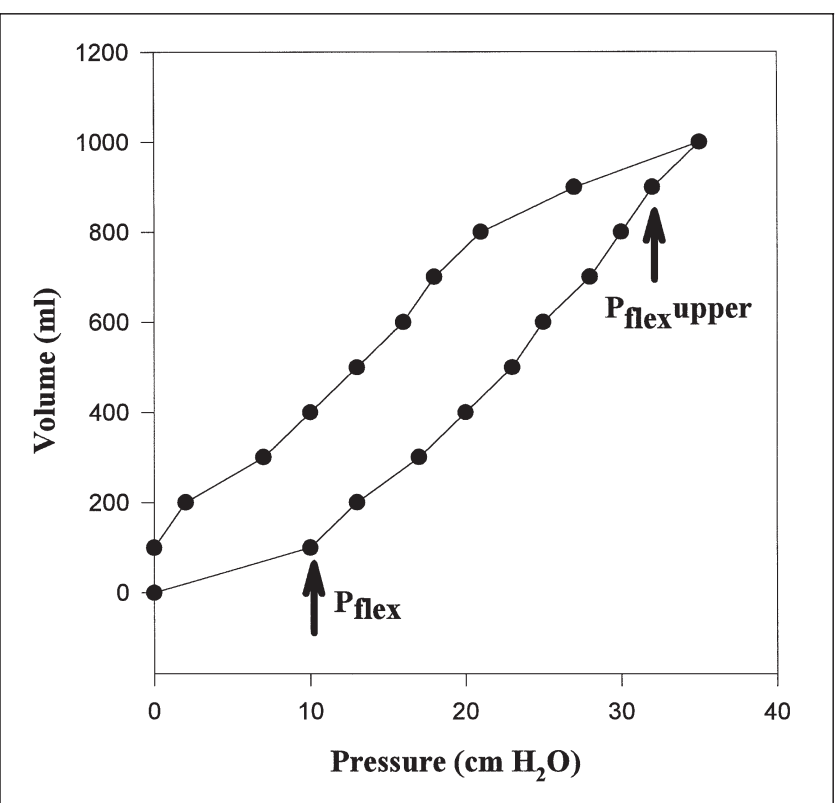

Figure 2) Typical static pressure-volume curve of a patient with acute respiratory distress syndrome, which demonstrates pertinent points to the prevention of ventilator-induced lung injury. The inflection point $\left(P_{\text {flex }}\right)$ or the critical opening pressure of the lungs in this example is at approximately $10 \mathrm{~cm} \mathrm{H}_{2} \mathrm{O}$. The upper inflection point (Pflexupper) where maximum distension of normal lung tissue occurs is slightly greater than $30 \mathrm{~cm} \mathrm{H}_{2} \mathrm{O}$. Based on current concepts of lung protective ventilation strategies, the end-expiratory pressure should be above $P_{\text {flex }}$ and the transpulmonary pressure below Pflexupper

attempt to recruit collapsed, consolidated and atelectatic lung; to prevent collapse and atelectasis; and to reduce $\mathrm{FiO}_{2}$ in order to avoid oxygen toxicity. Today, PEEP greater than $\mathrm{P}_{\text {flex }}$ should also be used as a means to prevent VILI. In most patients a $\mathrm{P}_{\text {flex }}$ is not present, but in those with acute lung injury (particularly the early stages of ARDS), $\mathrm{P}_{\text {flex }}$ does exist when measured on a static pressure-volume curve (16) (Figure 2). At times, measurements of static pressure-volume curves may not be feasible; thus, in patients with acute lung injury, high risk for ARDS and established ARDS, we gener-

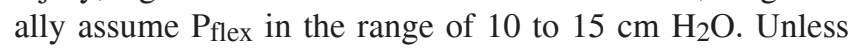
contraindicated, as a component of a LPVS, we use total PEEP (sum of delivered PEEP and intrinsic PEEP) in this range until the lung injury has resolved (defined as dissipation of bilateral pulmonary infiltrates and/or $\mathrm{FiO}_{2}$ less than $0.4)$.

Overdistension: Lung overdistension is thought to occur when PTP is greater than 30 to $35 \mathrm{~cm} \mathrm{H}_{2} \mathrm{O}$. When esophageal balloons are not available to measure PPL, peak PALV (plateau pressure) is generally used as a surrogate for PTP (this assumes a PPL close to 0, a situation that is not always true, especially in patients with massive ascites, pleural effusions, etc). The point of lung overdistension can also be measured with the aid of the static pressure-volume curve. On the ascending (inspiratory) limb there is a point where compli-

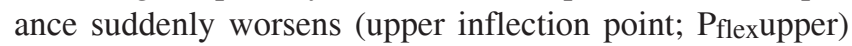
(Figure 2). For most patients ventilated with conventional VT

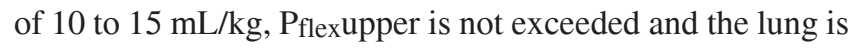




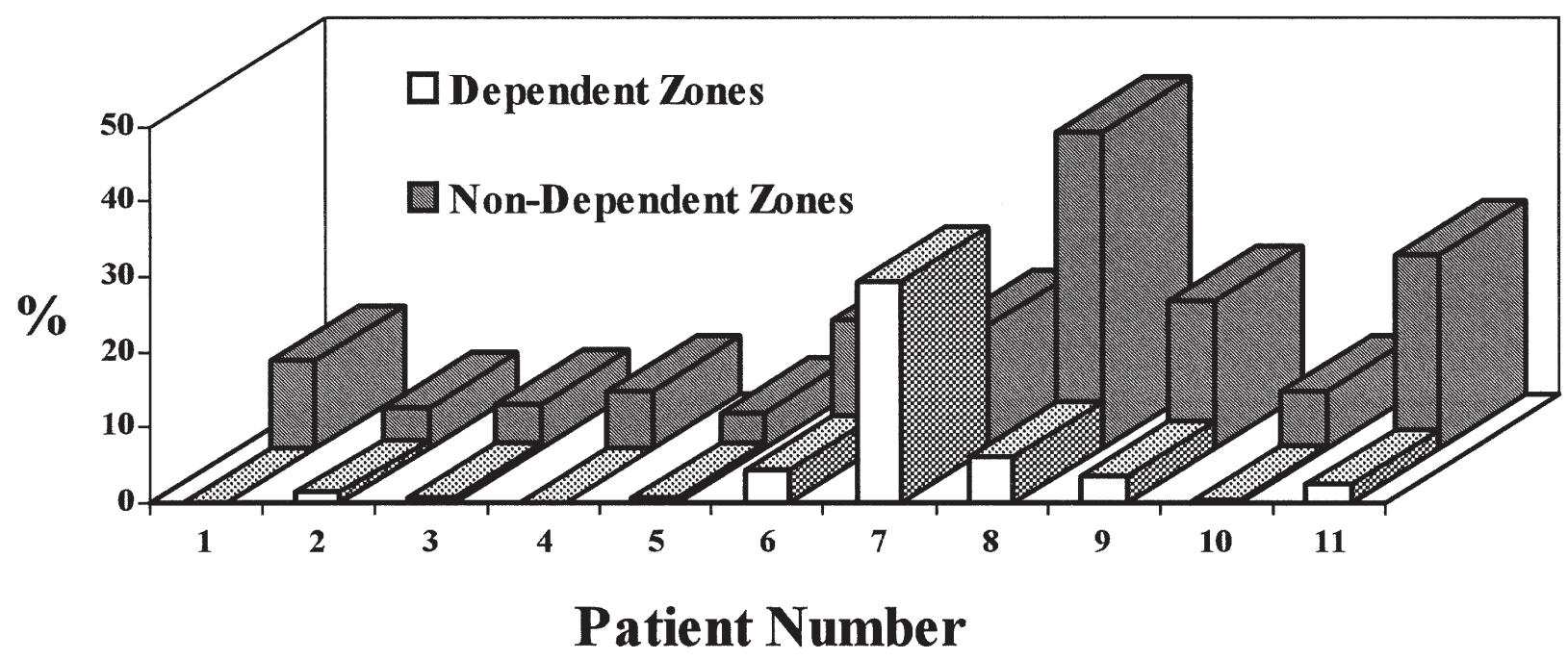

Figure 3) Percentage of lung area occupied by parenchymal air cysts (evidence of ventilator-induced lung injury) as assessed by computed tomographic $(C T)$ scan of the thorax in 11 patients with severe acute respiratory distress syndrome. CT scans were performed on a mean of

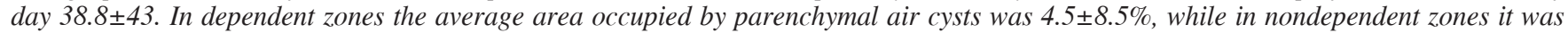
$14.9 \pm 11.3 \%$

not overdistended. However, the majority of patients with acute lung injury demonstrate a Pflexupper when exposed to VT of $10 \mathrm{~mL} / \mathrm{kg}$ (17). Overdistension occurs in this setting because a much lesser amount of lung is available for ventilation. This evidence has come from computed tomography (CT) scans that have refuted the commonly held misconception that pulmonary infiltrates in ARDS are found throughout all lung fields (as one may be led to believe by plain chest roentgenograms). CT scans have consistently demonstrated that pulmonary infiltrates (less available for ventilation) are usually greatest in dependent lung zones, with preservation of normal, more compliant lung in nondependent zones $(18,19)$. A small amount of the most healthy (nondependent) lung exposed to the VT usually reserved for the entire lung would lead one to expect overdistension to occur in that lung. Human autopsy studies have confirmed that, among other factors, histological evidence of barotrauma is correlated with the higher VT that the patients were exposed to (20). As well, there seems to be a predominance of intraparenchymal air cysts (evidence of VILI) as demonstrated on CT scan in nondependent lung zones in ventilated patients with ARDS (21) (Figure 3). Others have demonstrated that this evidence of VILI on CT scan is primarily in the dependent lung zones (22). This discrepancy in the location of the VILI may be best explained by the different mechanisms of VILI. If the lesion is due purely to overdistension, one would expect it to occur in nondependent lung zones where the most compliant lung is likely to be. However, if inadequate PEEP is the culprit, then one would expect this damage primarily in lung zones prone to collapse (dependent lung zones), as has been confirmed in animal studies (13). Wherever the injury is most predominant, the message remains the same: when caring for patients such as these, clinicians have a substantially reduced lung volume to work with. Thus, if conventional VT (10 to
$15 \mathrm{~mL} / \mathrm{kg}$ ) is used, the lung will be prone to overdistension and VILI.

Permissive hypercapnia: The problem of overdistension has led many to speculate that the cost of maintaining 'normal' $\mathrm{PaCO}_{2}$ (35 to $45 \mathrm{mmHg}$ ) in some patients is too great, and that perhaps $\mathrm{V}_{\mathrm{T}}$ should be reduced to avoid overdistension, even at the expense of accepting lower ventilation and at times a higher than 'normal' $\mathrm{PaCO}_{2}$ (permissive hypercapnia). Permissive hypercapnia is not a ventilation strategy in itself, but it is a potential component of an LPVS. Roupie et al (17) demonstrated that, in order to avoid overdistension (plateau pressure less than Pflexupper), permissive hypercapnia is required in the majority of patients with ARDS. Although permissive hypercapnia has been accepted as the standard of practice in ventilated patients with airflow obstruction, it has been recommended in patients with ARDS only in recent years (15). The first reported trial looking at a ventilation strategy for ARDS that incorporated permissive hypercapnia was very exciting because it achieved a marked reduction in mortality of $16 \%$, compared with an expected mortality of $39.6 \%$ (23). However, this trial has been criticized because it was not randomized or controlled. Controlled trials have demonstrated that reductions in VT to $6 \mathrm{~mL} / \mathrm{kg}$, compared with $12 \mathrm{~mL} / \mathrm{kg}$ without hypercapnia, are well tolerated and potentially associated with lower morbidity in general surgical intensive care unit patients (24). More recently, a randomized controlled trial involving 28 patients with early ARDS (15 randomized to an LPVS accepting permissive hypercapnia and 13 to a conventional ventilation strategy maintaining a normal $\mathrm{PaCO}_{2}$ ) demonstrated a better evolution of lung function in patients in the LPVS arm (25). In this small group of patients mortality was not reduced, but the likelihood is that in a larger group of patients this significant reduction in morbidity will be translated into a reduction 
in mortality. In fact, in a follow-up to this trial a decrease in mortality is occurring (personal communication).

Effects of hypercapnia: Much debate revolves around the potential adverse effects of permissive hypercapnia. Most of the literature recording the consequences of hypercapnia involves acute hypercapnia, which is likely to be very different from a more slowly induced chronic hypercapnia that occurs in this setting. Nonetheless the potential consequences of permissive hypercapnia and/or associated acidosis include impaired oxygenation (related to reduced ventilation pressures, effect on the alveolar gas equation, shift of the oxygen dissociation curve), catecholamine surge (resulting in increased cardiac output, heart rate, peripheral vascular resistance, systemic vascular resistance and blood pressure), direct vasodilation (raised intracranial pressure, coronary steal), increased need for sedation and paralysis (related to ventilatory drive), skeletal muscle weakness, myocardial depression, decreased seizure threshold, less response to defibrillation and inotropes, and increased blood letting (in order to follow blood gases more closely). Due to these potential concerns, permissive hypercapnia is generally avoided in patients with intracranial lesions, severe right- or left-sided heart failure, severe angina and predisposition to malignant arrhythmias. Otherwise, it is used with caution as a component of an LPVS while we anxiously await confirmation of the adverse effects.

Although no absolute guidelines can be given as to how high to allow $\mathrm{PaCO}_{2}$ to rise and how low to allow $\mathrm{pH}$ to drop when using ventilation strategies that incorporate permissive hypercapnia, clinicians need to be vigilant for the potential complications and to intervene when they become unacceptable. With the many tools available, intervention for the complications may be possible without exposing the patient to lung-damaging pressures and volumes. For example, if adverse effects of the high $\mathrm{PaCO}_{2}$ and associated acidosis are too great, clinicians have several options. These include reducing carbon dioxide production, such as by reducing temperature, inducing paralysis and avoiding overfeeding; reducing apparatus, anatomic and alveolar deadspace (by removing connectors or monitors attached to the endotracheal tube, high frequency ventilation, tracheal gas insufflation and inhaled nitric oxide augmenting lung perfusion); and treating metabolic acidosis (by dialysis, augmenting oxygen delivery and buffers). As well, when oxygenation is difficult to maintain $\left(\mathrm{SaO}_{2} 88 \%\right.$ to $90 \%$ or greater on $\mathrm{FiO}_{2}$ less than 0.6) using an LPVS, methods may be incorporated to improve oxygenation within the guidelines of the ventilation strategy by, for example, an increase in mean airway pressure (via higher PEEP, high frequency ventilation and inverse ratio ventilation); and improved ventilation-perfusion match-

\section{REFERENCES}

1. Peterson GW, Baier H. Incidence of pulmonary barotrauma in a medical ICU. Crit Care Med 1983;11:67-9.

2. Gammon RB, Shin MS, Groves RH, Hardin JM, Hsu C, Buchalter SE. Clinical risk factors for pulmonary barotrauma: a multivariate analysis. Am J Respir Crit Care Med 1995;152:1235-40.

3. Webb HH, Tierney DF. Experimental pulmonary edema due to
TABLE 1

Ten commandments of a lung protective ventilation strategy (LPVS)

1. An LPVS should be implemented immediately on intubation in all patients who do not have contraindications

2. Transpulmonary pressure should be maintained $<30$ to $35 \mathrm{~cm}$ $\mathrm{H}_{2} \mathrm{O}$

3. Unless contraindicated $\mathrm{FiO}_{2}$ should be kept as low as possible $(<0.6)$ to maintain minimally acceptable arterial saturation ( $88 \%$ to $90 \%)$

4. PEEP should be kept above the inflection point on the static pressure-volume curve until resolution of lung injury

5. Although not desired, permissive hypercapnia is often an acceptable necessary component of an LPVS

6. Clinicians should be aware of and vigilant for the adverse effects of permissive hypercapnia

7. Faced with unacceptable adverse effects of a high $\mathrm{PaCO}_{2}$ or low $\mathrm{pH}$, cliniclans should employ strategies to reduce these before ventilating outside the guidelines of an LPVS

8. Faced with unacceptable oxygenation $\left(\mathrm{FiO}_{2}>0.5 \pm \mathrm{SaO}_{2}\right.$ $<8 \%$ ) clinicians should employ strategies to improve oxygenation before ventilating outside the guidelines of an LPVS

9. When all else fails and patient safety necessitates ventilation outside the guidelines of an LPVS, reimplementation should begin as soon as possible

10. Patients are individuals and do not behave predictably; thus, proper mechanical ventilation requires repeated bedside reassessment by the clinician

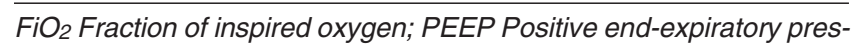
sure

ing, by repositioning (including an attempt at prone position), inhaled nitric oxide and augmented cardiac output. With all this in mind, Table 1 outlines the 'ten commandments' for implementing lung protective ventilation strategies.

\section{CONCLUSION}

Studies in animals have consistently demonstrated that VILI can occur in a very short time with the ventilator settings frequently used in intensive care units today. Human studies confirm that VILI is common and that (although not proven conclusively) when strategies are implemented to avoid VILI, morbidity and perhaps mortality can be reduced. Current recommendations for mechanical ventilation should include the early implementation of an LPVS (including the potential use of permissive hypercapnia) in all patients unless contraindicated. Clinicians should be aware of the potential complications of permissive hypercapnia and develop strategies to deal with these complications that, it is hoped, will avoid the need to venture beyond the recommendations of an LPVS. It is anticipated that broader use of current ventilation recommendations will yield improved patient care.

intermittent positive pressure ventilation with high inflation pressures. Protection by positive end expiratory pressure. Am Rev Respir Dis 1974; 110:556-65.

4. Dreyfuss D, Basset G, Soler P, Saumon G. Intermittent positive-pressure hyperventilation with high inflation pressures produces pulmonary microvascular injury in rats. Am Rev Respir Dis 1985;132:880-4. 
5. Parker JC, Hernandez LA, Longnecker GL, Peevy K, Johnson W. Lung edema caused by high peak inspiratory pressures in dogs. Role of increased microvascular filtration pressure and permeability. Am Rev Respir Dis 1990;142:321-8.

6. Kolobow T, Moretti MP, Fumagalli R, et al. Severe impairment in lung function induced by high peak airway pressure during mechanical ventilation. An experimental study. Am Rev Respir Dis 1987;135:312-5.

7. Cilley RE, Wang JY, Coran AG. Lung injury produced by moderate overinflation in rats. J Pediatr Surg 1993;28:488-95.

8. Dreyfuss D, Soler P, Basset G, Saumon G. High inflation pressure pulmonary edema. Respective effects of high airway pressure, high tidal volume and positive end-expiratory pressure. Am Rev Respir Dis 1988;137:1159-64.

9. Stewart TE, Slutsky AS. Mechanical ventilation: a shifting philosophy. Curr Opin Crit Care 1995;1:49-56.

10. Hernandez LA, Peevy KJ, Moise AA, Parker JC. Chest wall restriction limits high airway pressure-induced lung injury in young rabbits. J Appl Physiol 1989;66:2364-8.

11. Dreyfuss D, Saumon G. Role of tidal volume, FRC, and endinspiratory volume in the development of pulmonary edema following mechanical ventilation. Am Rev Respir Dis 1993;148:1194-203.

12. Sandhar BK, Niblett DJ, Argiras EP, Dunnill MS, Sykes MK. Effects of positive end-expiratory pressure on hyaline membrane formation in a rabbit model of the neonatal respiratory distress syndrome. Intensive Care Med 1988;14:538-46.

13. Corbridge TC, Wood LDH, Crawford GP, Chudoba MJ, Yanos J, Sznajder JI. Adverse effects of large tidal volume and low PEEP in canine acid aspiration. Am Rev Respir Dis 1990;142:311-5.

14. Muscedere JG, Mullen JBM, Gan K, Slutsky AS. Tidal ventilation at low airway pressures can augment lung injury. Am J Respir Crit Care Med 1994;149:1327-34.
15. Slutsky AS. Mechanical ventilation. Chest 1993;104:1833-59.

16. Matamis D, Lemaire F, Harf A, Brun-Buisson C, Ansquer JC, Atlan G. Total respiratory pressure-volume curves in the adult respiratory distress syndrome. Chest 1984;86:58-66.

17. Roupie E, Dambrosio M, Servillo G, et al. Titration of tidal volume and induced hypercapnia in acute respiratory distress syndrome. Am J Respir Crit Care Med 1995;152:121-8.

18. Gattinoni L, Pesenti A, Torresin A, et al. Adult respiratory distress syndrome profiles by computed tomography. J Thorac Imaging 1986;1:25-30.

19. Maunder RJ, Shuman WP, McHugh JW, Marglin SI, Butler J. Preservation of normal lung regions in the adult respiratory distress syndrome. JAMA 1986;255:2463-5.

20. Rouby JJ, Lherm T, Martin de Lassale E, et al. Histologic aspects of pulmonary barotrauma in critically ill patients with acute respiratory failure. Intensive Care Med 1993;19:383-9.

21. Stewart TE, Toth JL, Higgins RJ, et al. Barotrauma in severe ARDS is greatest in non dependent lung regions evaluation by computed tomography. Crit Care Med 1993;21:S284. (Abst)

22. Gattinoni L, Bombino M, Pelosi P, et al. Lung structure and function in different stages of severe adult respiratory distress syndrome. JAMA 1994;271:1772-9.

23. Hickling KG, Henderson SJ, Jackson R. Low mortality associated with low volume pressure limited ventilation with permissive hypercapnia in severe adult respiratory distress syndrome. Intensive Care Med 1990;16:372-7.

24. Lee PC, Helsmortel CM, Cohn SM, Fink MP. Are low tidal volumes safe? Chest 1990;97:425-9.

25. Amato MBP, Barbas CSV, Medeiros DM, et al. Beneficial effects of the 'open lung approach' with low distending pressures in acute respiratory distress syndrome. Am J Respir Crit Care Med $1995 ; 152: 1835-46$ 


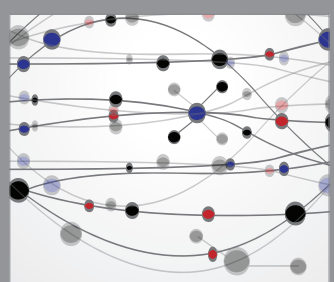

The Scientific World Journal
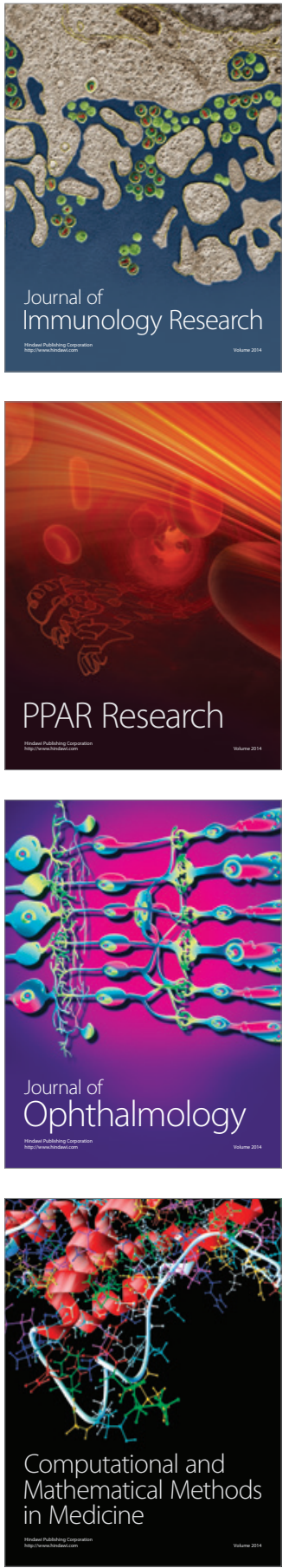

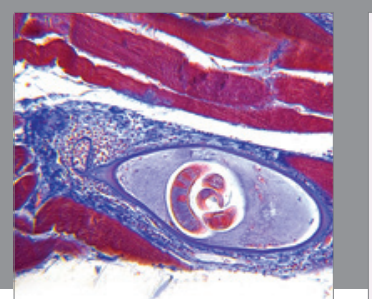

Gastroenterology Research and Practice

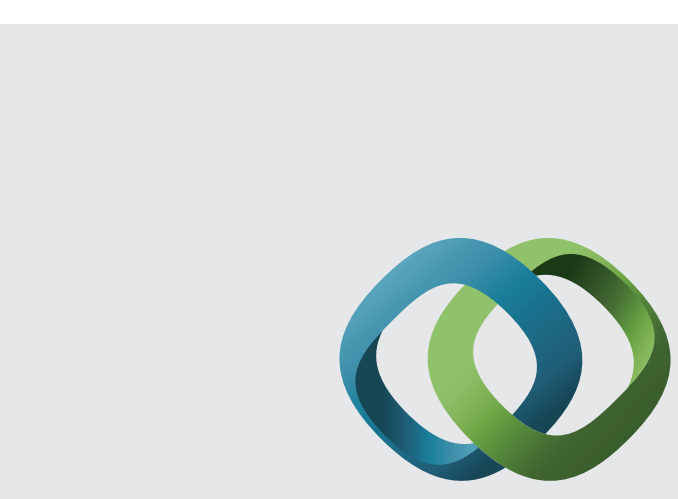

\section{Hindawi}

Submit your manuscripts at

http://www.hindawi.com
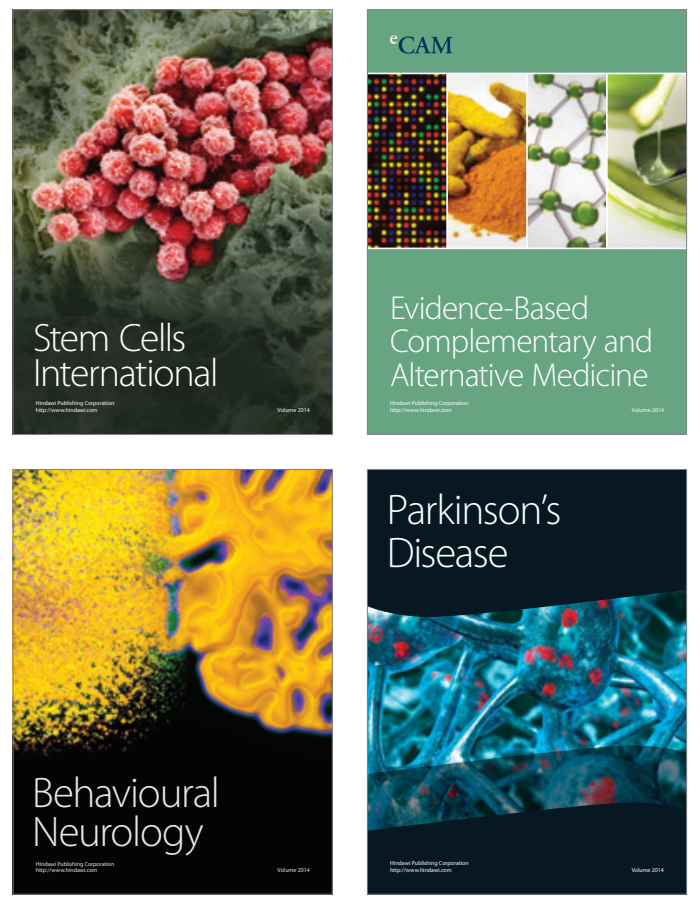
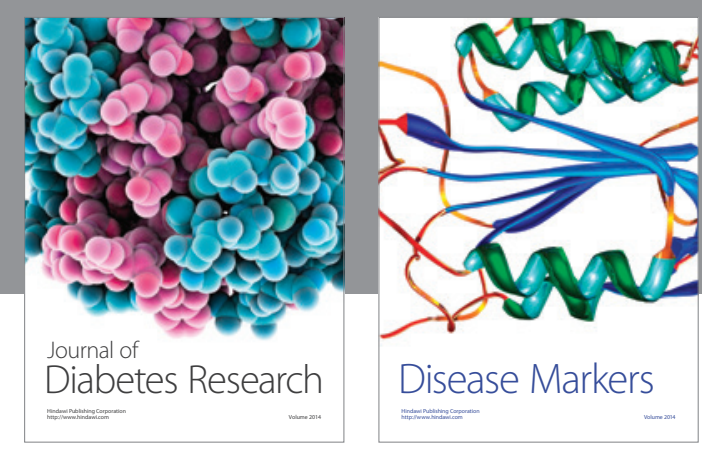

Disease Markers
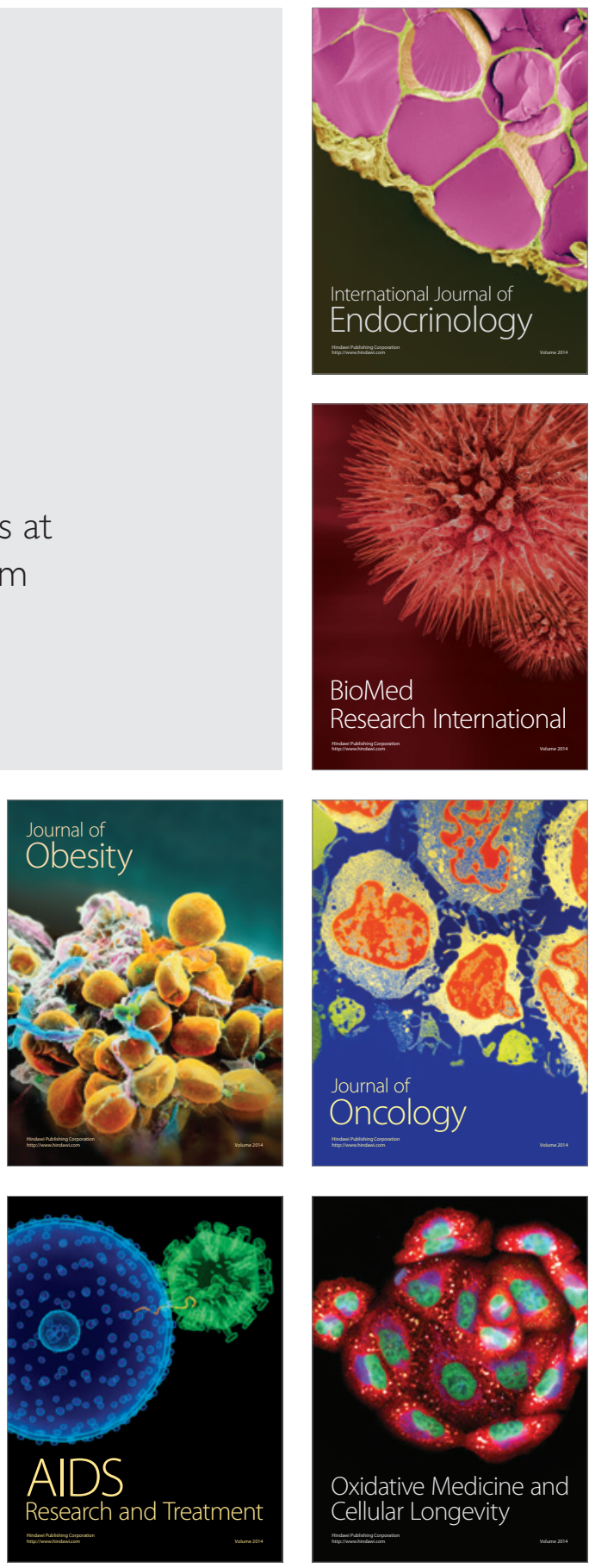